\title{
A Retrospective Study on the Pyogenic Pathogens and Their Antibiotic Susceptibility Patterns along with the ES $\beta$ L Production
}

\author{
Anindita Chakraborty ${ }^{1,2 *}$, Debadatta Dhar Chanda ${ }^{2 *}$, Nilanjana Choudhury², N. G. Manjula1\#, \\ B. M. Shilpa ${ }^{1 \#}$ \\ ${ }^{1}$ Department of Microbiology, School of Basic and Applied Sciences (SBAS), Dayananda Sagar University, Bengaluru, Karnataka \\ ${ }^{2}$ Department of Microbiology, Silchar Medical College and Hospital, Assam, India \\ Email: "manjulang-sbas@dsu.edu.in,"shilpa-sbas@dsu.edu.in, "shilpa.siddi@gmail.com
}

How to cite this paper: Chakraborty, A., Chanda, D.D., Choudhury, N., Manjula, N.G. and Shilpa, B.M. (2021) A Retrospective Study on the Pyogenic Pathogens and Their Antibiotic Susceptibility Patterns along with the ES $\beta \mathrm{L}$ Production. Advances in Microbiology, 11, 317-326.

https://doi.org/10.4236/aim.2021.116024

Received: May 20, 2021

Accepted: June 22, 2021

Published: June 25, 2021

Copyright $\odot 2021$ by author(s) and Scientific Research Publishing Inc. This work is licensed under the Creative Commons Attribution-NonCommercial International License (CC BY-NC 4.0). http://creativecommons.org/licenses/by-nc/4.0/

\begin{abstract}
Pyogenic infections are caused by various pathogens leading to pus formation and that can be attributed due to a wound either through accident or during surgery leading to infection spread. There are pathogenic strains that are not uncommon in hospital settings like Staphylococcus aureus, Klebsiella pneumoniae, Pseudomonas aeruginosa, Acinetobacter etc., that are multidrug resistant (MDR) and are a cause of concern. The bacteriological profile in the pyogenic infections tends to be same but there is a vast difference with the antibiotic resistant patterns in different hospital settings. Hence, the aim was to study the antibiotic susceptibility profiles and Extended spectrum $\beta$ eta Lactamases (ES $\beta \mathrm{L}$ ) production in these pathogens. A prospective study was carried out in Silchar Medical College and Hospital Assam, India, over a four-month period from February to May 2021. The samples were processed using Blood and MacConkey's agar. Further, these isolated pathogens were identified by standard morphological, cultural and biochemical tests. The antibiotic susceptibility test was conducted by Kirby Bauer disc diffusion method and ES $\beta$ L production was detected by using combined disk diffusion test. It was observed that the identified pathogens had an incidence rate of $84.2 \%$ and further revealed that Gram negative had a higher incidence rate compared to Gram positive with $59.8 \%$. The pathogens isolated from pus samples had a maximum of Klebsiella sps (19.64\%) and the lowest was E. coli with $5.36 \%$. Antibiotic susceptibility test (AST) of Gram-negative bacterial isolates showed the highest incidence with aztreonam (40.6\%) and the lowest was observed in Piperacillin/Tazobactam with $7.5 \%$. The only Gram positive
\end{abstract}


was observed in our study, Staphylococcus aureus had the highest resistance in amikacin with $80 \%$ and interestingly, all the isolates were sensitive to Linezolid with $100 \%$. There is a high rise and spreading with the multi-drug resistance (MDR) strains along with $\mathrm{ES} \beta \mathrm{L}$ production and it was observed in our studies that these pathogens had an incidence rate of $18.5 \%$. The highest was $58.1 \%$ in Pseudomonas sps. None of Proteus sps were found to be ES $\beta \mathrm{L}$ producers. To combat resistance, the irrational use of antibiotics should be avoided and surveillance of the rising multidrug species regularly helps in implementing better therapeutic options to reduce the morbidity and mortality.

\section{Keywords}

Antibiotic Susceptibility Test, Pus, ES $\beta$ L, MDR

\section{Introduction}

Infectious diseases are an important cause of morbidity and mortality in humans, particularly in developing countries like India. Microbial pathogens can enter the human skin and the soft tissues causing infections during trauma, burn injuries and surgeries that lead to pus formation which consists of white to yellow fluid consisting of dead WBCs, cellular debris and necrotic tissues [1] [2] [3]. It has been reported that the incidence rate of wound sepsis in India is from $10 \%$ to $33 \%$ [4]. The diversity and the causative agents are basically influenced by the predisposing factors like the anatomical location: type and level of perfusion in tissues and the efficacy of antimicrobial agents in host response [5]. These pathogens in hospital acquired tend to prolong the hospitalisation, increase morbidity and are a huge economic burden to the country [6]. Antibiotic resistance has emerged drastically and rapidly spreading by the pathogens that are a threat to the public health worldwide. Hospital acquired infections in pus have seen a steep rise with these MDR Gram-negative bacterial strains that include $A$. baumannii, E. coli, K. pneumoniae, $P$. aeruginosa, and Gram-positive methicillin-resistant $S$. aureus (MRSA) which is due to the inadequate dose and misperception of antibiotics [7] [8].

Pyogenic infections are significant as they encounter infectious diseases in hospitals worldwide that are associated with high morbidity and to reduce long term complications, the antimicrobial regimes are recommended [9]. The advancement in diagnostic treatment and treatment options in developing countries are further challenging due to the MDR strains that are fast evolving. There has been a rapid emergence of MDR Gram positive and Gram-negative bacterial isolates that are increasing with pyogenic infections in recent years [10]. The crisis of resistance among the pyogenic pathogens can be attributed due to the inappropriate use of antibiotic agents particularly in developing countries [11]. With the rapid emerging MDR strains and limited treatment options and no 
new discovery of new classes of antibiotics [12], the objective of this study is to characterize the bacterial pathogens from pus samples and to determine their antibiotic susceptibilities to various generations of antibiotics commonly used in chemotherapeutic interventions.

$\beta$-lactam antibiotics are the most common drugs that are used for the treatment of Gram-negative bacteria and due to their continuous misuse, have led to the resistance in these pathogens worldwide [13]. Further, these pathogens have induced mutations and continuous production of $\beta$-lactamases to counter the effects of these beta lactam drugs. There has been a significant increase in these ES $\beta \mathrm{L}$ producers causing various infections worldwide [14] [15]. These ES $\beta \mathrm{L}$ producers causing nosocomial infections have resulted in a steep rise in their incidence in recent years with high morbidity-mortality rates due to these $\beta$-lactamases resistant MDR strains. Rapid identification of ES $\beta \mathrm{L}$ pathogens and their antibiotic resistance patterns will help the clinicians to select appropriate drug regimens like combination therapy and reduce their further spread [16].

\section{Materials and Methods}

Sample Collection and Characterization: The pus samples were collected by sterile syringe aspiration and by sterile swabs from inpatients and outpatients of different wards from Silchar Medical College and Hospital Assam, India, over a four-month period from February to May 2021. A total of 133 pus samples were collected over a period of three months from January 2021 to March 2021 with accordance to ethical guidelines. The pus samples were collected from different departments such as Orthopaedic, Surgery, ENT, Paediatric and Dermatology (furuncles, pustules and abrasions). The samples were maintained in Cary-Blair transport media until further processing. Isolation of the pathogens was carried on Blood agar (with 5\% sheep blood), Chocolate agar and MacConkey's agar plates (Hi-Media, Mumbai, India), incubated aerobically at $37^{\circ} \mathrm{C}$ for $24-48 \mathrm{~h}$. Further, clinical isolates were identified and characterised by microscopic, cultural characteristics and biochemical tests using standard microbiological methods.

\section{Antibiotic Sensitivity Test (AST).}

Antibiotics discs containing Amoxyclav (AMC-30 $\mu$ ), Ciprofloxacin (CIP-5 $\mu \mathrm{g})$, Clindamycin (CD-2 $\mu \mathrm{g})$, Cefoxitin (CX-30 $\mu \mathrm{g})$, Linezolid (LZ-10 $\mu \mathrm{g})$, Cotrimoxazole (COT-25 $\mu \mathrm{g})$, Azithromycin (AZM-15 $\mu \mathrm{g})$, Cefuroxime (CXM-30 $\mu \mathrm{g})$, Amikacin (AK-30 $\mu \mathrm{g})$, Cefixime (CFM-5 $\mu \mathrm{g})$, Piperacillin/Tazobactam (TZP-100/10 $\mu \mathrm{g}$ ), Levofloxacin (LE-5 $\mu \mathrm{g}$ ), Ceftriaxone (CTR-30 $\mu \mathrm{g}$ ), Cefepime (CPM-5 $\mu \mathrm{g}$ ), Aztreonam (AT-30 $\mu \mathrm{g}$ ), Cef0perazone (CPZ-75 $\mu \mathrm{g}$ ), Imipenem or Meropenem (IPM or MRP-10 $\mu \mathrm{g}$ ) were used for the studies. Antibiotic susceptibilities of the bacterial isolates were determined according to the method recommended by the Clinical and Laboratory Standards Institute (CLSI) guidelines. Briefly, inoculates were prepared for each bacterial isolate by adjusting the turbidity to $0.5 \mathrm{McF}$ arland standard and spread on Muller-Hinton agar plates. An- 
tibiotic discs (Hi-Media, Mumbai, India) were placed on the agar plates and incubated overnight at $37^{\circ} \mathrm{C}$ for $24 \mathrm{~h}$. The zones of inhibition were measured and the isolates were classified as sensitive, intermediate, and resistant according to CLSI guidelines [17].

\section{Phenotypic ES $\beta \mathrm{L}$ detection:}

Detection of ES $\beta$ L-producing organisms was performed by Double Disc Synergy Test (DDST) method following the CLSI recommendations. The test suspension was prepared for each pure bacterial isolate according to $0.5 \mathrm{McF}$ arland standard that was swabbed on Mueller-Hinton agar. After 15 minutes the cultured plates were placed with pairs of antibiotic disks containing Cefotaxime (30 $\mu \mathrm{g})$ with Cefotaxime/Clavulanic acid $(30 / 10 \mu \mathrm{g})$ at a distance of $20 \mathrm{~mm}$ apart from each other. The plates were incubated for $24 \mathrm{~h}$ at $37^{\circ} \mathrm{C}$. The results were interpreted by measuring the diameter of zone of inhibition. According to CLSI guidelines, an increase in $\geq 5 \mathrm{~mm}$ in the zone diameter around the clavulanic acid combination disks versus the same disks alone confirmed the organism as ES $\beta$ L producers.

\section{Results}

The distribution pattern of the collected pus samples on the basis of gender ratio showed that there were 82 male and 51 female patients. It was observed that the greater percentage of $62 \%$ was observed in males than females $(38 \%)$. Out of the 133 samples processed $112(89.2 \%)$ were found to be culture positive. The highest incidence was observed in the age group of 21 - 40 years with an incidence of $43.6 \%$, followed by, 1 - 20 years with $23.3 \%$ and the low incidence was observed in the age group of 60 years and above with $12 \%$.

Gram negative isolates had an incidence of $59.8 \%$ (67 isolates) while, Gram positive isolates were $40.18 \%$ (45 isolates). Our study revealed that the most predominant Gram negative pathogen was Klebsiella sps with an incidence rate of $19.64 \%$, followed by Pseudomonas sps (15.17\%), Acinetobacter sps $10.71 \%$, Proteus sps $8.93 \%$ and E. coli $5.36 \%$. Among the Gram positive bacteria, the most predominant pathogen isolated was Staphylococcus aureus with a rate of $40.18 \%$ (Figure 1).

Types of microbes isolated from pus sample

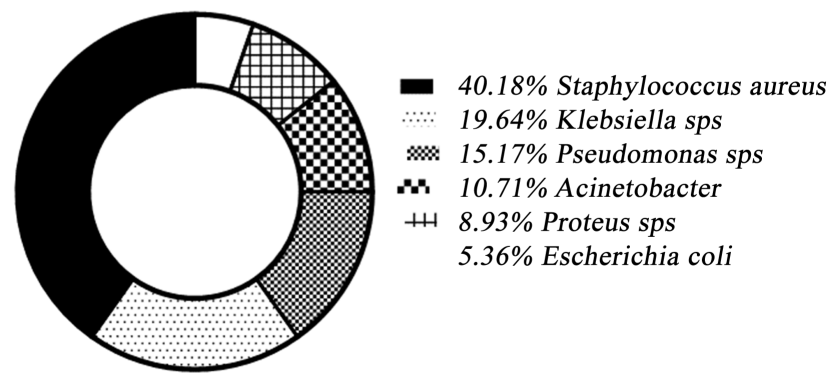

Figure 1. Percent incidence rate of different microbes isolated from pus samples. 
The antibiotic susceptibility test results of $S$. aureus, the only Gram positive bacteria isolated, revealed a highest resistance rate to the antibiotic Amikacin with $80.4 \%$, followed by Levofloxacin (71.32\%), Cefuroxime (61.7\%), Cotrimoxazole (53.3\%), Cefoxitin (37.77\%) and Ciprofloxacin (36\%). While, Amoxyclav (22.2\%), Clindamycin (11.11\%) showed moderate resistance, and Azithromycin (4.4\%) showed a low resistance rate. Interestingly, all the Gram positive isolates were sensitive to Linezolid with $100 \%$ (Figure 2).

The AST of Gram negative bacilli revealed that a total of $40.6 \%$ showed a highest resistance rate to Aztreonam, followed by cefepime (30\%), Levofloxacin (25.5\%), Amikacin (20.3\%), Ceftriaxone (17.2\%), Cefaperozone (13.5\%). A moderate resistance rate was observed with Imipenem/Meropenem (13.5\%) and Cefixime (15.7\%). Lowest was observed in Piperacillin/tazobactam with 7.5\%.

With respect to the different pathogens, AST results were found to be varying. The study showed that in case of Klebsiella sps, the highest resistance is observed with cefepime (81.82\%) and lowest in Piperacillin/Tazobactam (9.09\%) however, Acinetobacter sps showed highest with Ciprofloxacin (83.3\%) and lowest in ceftriaxone (16.66\%). Proteus sps were found to be resistant to amikacin antibiotic with a rate of $60 \%$ and all isolates were sensitive to and Meropenem. The results in E. coli showed resistant to Cefaperazone (66.66\%) and sensitive to Meropenem with (100\%). Pseudomonas sps showed higher resistant rate to some of the $\beta$-lactam antibiotics, the highest being to Cefaperazone (70.59\%) and the lowest in Piperacillin/tazobactam (11.7\%) as observed in Figure 3 and Figure 4 for all the Gram negative pathogens. The only Gram positive isolated from pus samples, S. aureus has a highest resistant to Amikacin with $79.24 \%$ and Linezolid showed no resistant.

The misuse of $\beta$-lactam drugs has given rise to MDR pathogens which is alarming situation worldwide. It has been observed that the overall incidence rate of ES $\beta$ L production with respect to the Gram negative pathogens was found to be $18.5 \%$. The highest ES $\beta \mathrm{L}$ producers were found to be $58.1 \%$ in Pseudomonas sps, followed by Acinetobacter sps (50\%), Klebsiella sps (30.13\%) and E. coli (33.3\%). However, none of the Proteus sps were found to be ES $\beta \mathrm{L}$ producers (Figure 5).

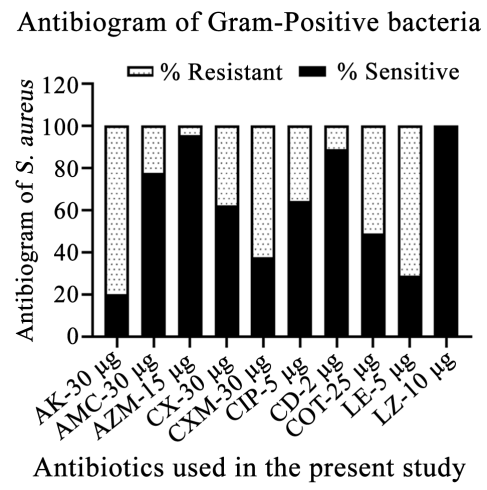

Figure 2. Antibiotic susceptibility pattern for Staphylococcus aureus, the only Gram positive isolated in the study. 


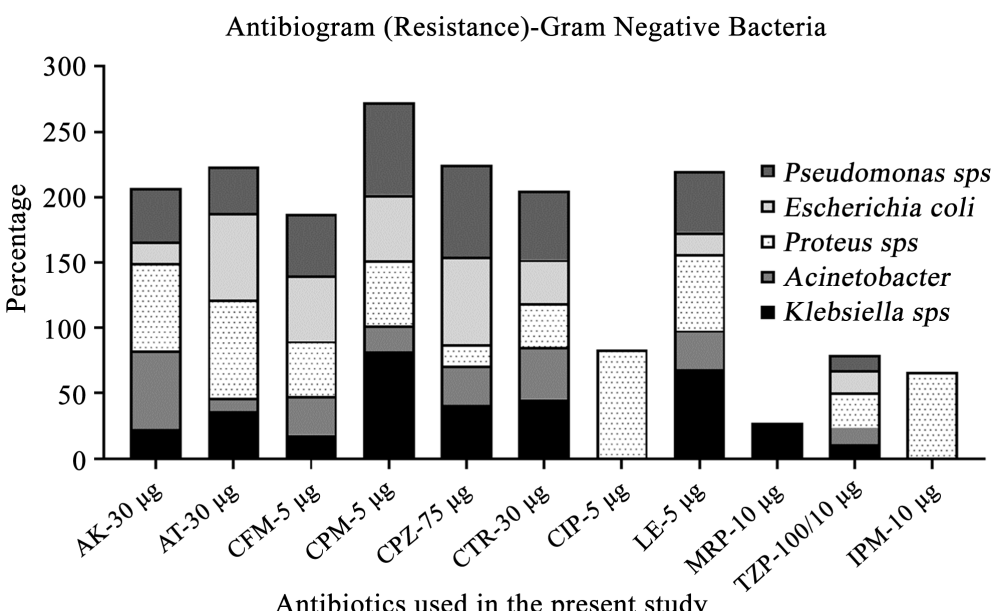

Figure 3. Antibiotic susceptibility pattern of Gram negative bacteria with respect to the resistance rate.

Antibiogram (Sensitive)-Gram Negative Bacteria

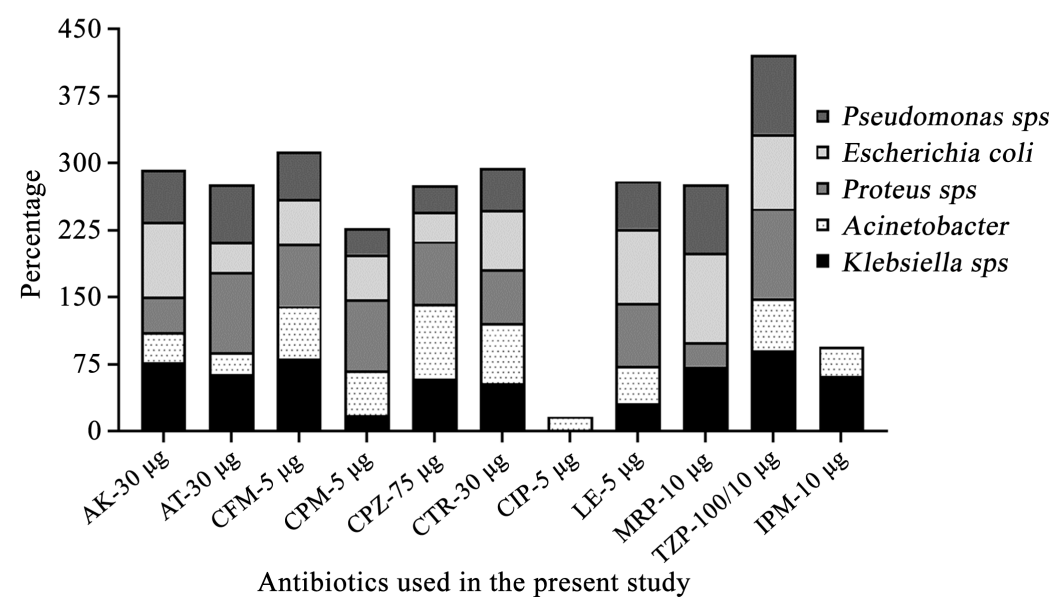

Figure 4. Antibiotic susceptibility pattern of Gram negative bacteria with respect to the sensitivity.

ESBL Producers

(Cefotaxime/Clavulanic acid)

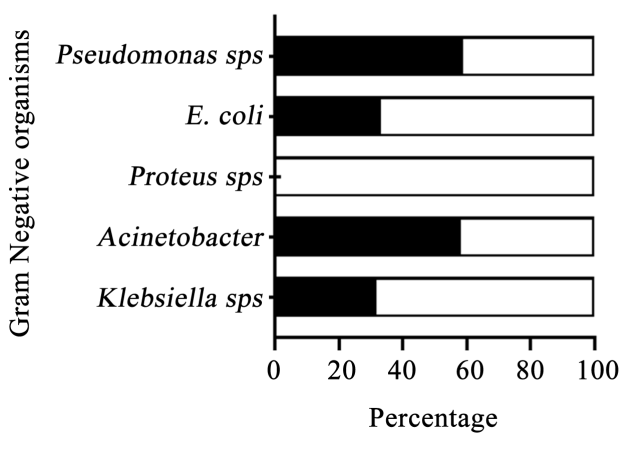

ロ Sensitive $\%$ Resistance

Figure 5. Percent incidence rate of $\mathrm{ES} \beta \mathrm{L}$ producers in different pathogens isolated from pus samples. 


\section{Discussion}

Pyrogenic infections that are characterised by local and systemic inflammations can be either due to single organism or multiple pathogens. The study revealed that $84.2 \%$ (112 samples) were positive for the isolation of pathogens from pus samples that was higher compared to the reports of [18]. The aetiological agents include Gram positive and Gram negative bacteria like Staphylococcus aureus, Enterococci, Pseudomonas aeruginosa, Escherichia coli, Klebsiella sps and Proteus sps. [19]. The study conducted includes both Gram positive and Gram negative pathogens. The predominant were Gram negative bacteria (59.8\%) that was almost in accordance with the other findings [20] [21].

The most common Gram negative pathogens isolated include Klebsiella sps (40.18\%), followed by Pseudomonas sps (15.17\%), Acinetobacter sps $10.71 \%$, Proteus sps $8.93 \%$ and E. coli $5.36 \%$. These are the most commonly found pathogens in hospital settings and are found to be MDR pathogens. However, there is a variation in the aetiological agents in different studies [20]. Among the Gram positive bacteria, the only and most predominant pathogen isolated was $S$. aureus with a rate of $40.18 \%$. While, the studies showed by [20] and [22] had other strains like CONS and Enterococci which was absent in the present studies.

Several reporters have shown the implications by different microorganisms that include Pseudomonas, Staphylococcus, Streptococcus, Klebsiella, and E. coli in wound infections [7]. It has been very well noted that $S$. aureus and specially MRSA are the major cause of soft tissue infections in hospitalised settings [23].

The study revealed that most of the Gram negative isolated in the pus samples had the lowest resistance to Piperacillin/Tazobactam (7.5\%) and Meropenem and Imipenem (13.5\%) which is similar to the other reports [20]. The only isolated Gram-positive cocci, $S$. aureus was found to be totally sensitive to Linezolid and Vancomycin with $100 \%$ as compared to the results conducted with a lesser resistance rate by [24] and same as our study [24]. With the increasing antibiotic resistance with the pathogens, it becomes mandatory to select and prescribe the antibiotics with appropriate dosage and duration. Our study reported a high MDR in various organisms like E. coli, $S$. aureus, $K$. pneumoniae and $P$. aeruginosa isolated from pus samples. Therefore, it becomes utmost essential to formulate the antibiotic policies and control measures that are suitable and essential [26]. The study also revealed the Gram negative isolates were resistant to cephalosporins but were well susceptible to amikacin and imipenem as was observed in the other study too [25]. $\beta$-lactamases are responsible for resistance to the $\beta$-lactam antibiotics and thus rendering these antimicrobials ineffective. The present study revealed ES $\beta \mathrm{L}$ producers with an incidence of $18.5 \%$. The highest $58.1 \%$ in Pseudomonas sps and $100 \%$ susceptibility was seen in Proteus sps. [27].

\section{Conclusion}

It has been observed that pyogenic infections are the most prevalent in the 
hospital settings and MDR pathogens being Staphylococcus aureus, followed by E. coli, $P$. aeruginosa, K. pneumoniae, P. mirabilis, and others. These MDR pathogens exhibit different levels of antibiotic resistance to different classes of antibiotics. There also has been an alarming rise in the ES $\beta \mathrm{L}$ producers by these pathogens and their spread throughout the world which is a serious problem. To combat the resistance by these microbes, it becomes necessary to stop the irrational use of antibiotics. There needs to be proper susceptibility data that can be used to implement hospital antibiotic policy. Strict health policies, continuous monitoring and reporting of antibiotic resistance will help in implementing better therapeutic drugs to combat diseases and reduce morbidity and mortality.

\section{Conflicts of Interest}

The authors declare no conflicts of interest regarding the publication of this paper.

\section{References}

[1] Cogen, A.L., Nizet, V. and Gallo, R.L. (2008) Skin Microbiota: A Source of Disease or Defence? British Journal of Dermatology, 158, 442-455. https://doi.org/10.1111/j.1365-2133.2008.08437.x

[2] Dryden, M.S. (2010) Complicated Skin and Soft Tissue Infection. Journal of Antimicrobial Chemotherapy, 65, iii35-iii44. https://doi.org/10.1093/jac/dkq302

[3] Scalise, A., Bianchi, A., Tartaglione, C., Bolletta, E., Pierangeli, M., Torresetti, M., Marazzi, M. and Di Benedetto. G. (2015) Microenvironment and Microbiology of Skin Wounds: The Role of Bacterial Biofilms and Related Factors. Seminars in Vascular Surgery, 28, 151-159. https://doi.org/10.1053/j.semvascsurg.2016.01.003

[4] Mantravadi, H., Chinthaparthi, M. and Shravani, V. (2015) Aerobic Isolates in Pus and Their Antibiotic Sensitivity Pattern: A Study Conducted in a Teaching Hospital in Andhra Pradesh. International Journal of Medical Science and Public Health, 4, 1076. https://doi.org/10.5455/ijmsph.2015.12012015225

[5] Overturf, G.D. (1986) Pyogenic Bacterial Infections of the CNS. Neurologic Clinics, 4, 69-90. https://doi.org/10.1016/S0733-8619(18)30989-7

[6] Bowler, P.G., Duerden, B.I. and Armstrong, D.G. (2001) Wound Microbiology and Associated Approaches to Wound Management. Clinical Microbiology Reviews, 14, 244-269. https://doi.org/10.1128/CMR.14.2.244-269.2001

[7] Misic, A. M., Gardner, S.E. and Grice, E.A. (2014) The Wound Microbiome: Modern Approaches to Examining the Role of Microorganisms in Impaired Chronic Wound Healing. Advances in Wound Care, 3, 502-510. https://doi.org/10.1089/wound.2012.0397

[8] Iredell, J., Brown, J. and Tagg, K. (2016) Antibiotic Resistance in Enterobacteriaceae: Mechanisms and Clinical Implications. BMJ, 352, h6420. https://doi.org/10.1136/bmj.h6420

[9] Muluye, D., Wondimeneh, Y., Ferede, G., Nega, T., Adane, K., Biadgo, B., Tesfa, H. and Moges, F. (2014) Bacterial Isolates and Their Antibiotic Susceptibility Patterns among Patients with Pus and/or Wound Discharge at Gondar University Hospital. BMC Research Notes, 7, Article No. 619. https://doi.org/10.1186/1756-0500-7-619

[10] Trojan, R., Razdan, L. and Singh, N. (2016) Antibiotic Susceptibility Patterns of 
Bacterial Isolates from Pus Samples in a Tertiary Care Hospital of Punjab, India. International Journal of Microbiology, 2016, Article ID: 9302692. https://doi.org/10.1155/2016/9302692

[11] Pondei, K., Fente, B.G. and Oladapo, O. (2013) Current Microbial Isolates from Wound Swabs, Their Culture and Sensitivity Pattern at the Niger Delta University Teaching Hospital, Okolobiri, Nigeria. Tropical Medicine and Health, 41, 49-53. https://doi.org/10.2149/tmh.2012-14

[12] Cerceo, E., Deitelzweig, S.B., Sherman, B.M. and Amin, A.N. (2016) Multidrug-Resistant Gram-Negative Bacterial Infections in the Hospital Setting: Overview, Implications for Clinical Practice, and Emerging Treatment Options. Microbial Drug Resistance, 22, 412-431. https://doi.org/10.1089/mdr.2015.0220

[13] Shaikh, S., Fatima, J., Shakil, S., Rizvi, S.M. and Kamal, M.A. (2015) Antibiotic Resistance and Extended Spectrum Beta-Lactamases: Types, Epidemiology and Treatment. Saudi Journal of Biological Sciences, 22, 90-101.

https://doi.org/10.1016/j.sjbs.2014.08.002

[14] Mirza, S., Jadhav, S., Misra, R.N. and Das, N.K. (2019) Coexistence of $\beta$-Lactamases in Community-Acquired Infections in a Tertiary Care Hospital in India. International Journal of Microbiology, 2019, Article ID: 7019578. https://doi.org/10.1155/2019/7019578

[15] Shama, M., Murugesan, K. and Vijayan, H. (2018) Isolation Identification and Antibiotic Sensitivity Pattern of Pyogens from Pyogenic Pathogens. Biomedical and Pharmacology Journal, 11, 463-468. https://doi.org/10.13005/bpj/1395

[16] Nagshetty, K., Shilpa, B.M., Patil, S.A. Shivannavar, C.T. and Manjula, N.G. (2021) An Overview of Extended Spectrum Beta Lactamases and Metallo Beta Lactamases. Advances in Microbiology, 11, 37-62. https://www.scirp.org/journal/aim https://doi.org/10.4236/aim.2021.111004

[17] Clinical and Laboratory Standards Institute (2018) Performance Standards for Antimicrobial Susceptibility Testing. 28th Edition, CLSI Supplement M100-S23, CLSI, Wayne.

[18] Sirigadha, K., Sajjan, C.A., Swetha, M. and Shalini, S. (2016) Characterization and Resistance Pattern of Bacterial Isolates from Pus Samples in a Tertiary Care Hospital, Karimnagar. Tropical Journal of Pathology and Microbiology, 2, 49-54. https://doi.org/10.17511/jopm.2016.i02.03

[19] Maniyan, G. (2017) A Study on Aerobic Bacteriological Profile and Antimicrobial Susceptibility Pattern of Isolates from Pus Samples in a Tertiary Care Hospital. International Journal of Biosciences, 6, 5317. https://doi.org/10.21746/ijbio.2017.03.007

[20] Wadekar, M., Sathish, J.V. and Jayashree, P.C. (2020) Bacteriological Profile of Pus Samples and Their Antibiotic Susceptibility Pattern. Indian Journal of Microbiology Research, 7, 43-47. https://doi.org/10.18231/j.ijmr.2020.010

[21] Sharma, M., Pathak, S. and Shrivastava, P. (2013) Prevalence and Antibiogram of Extended Spectrum b-Lactamase (ESBL) Producing Gram Negative Bacilli and Further Molecular Characterization of ESBL Producing Escherichia coli and Klebsiella spp. Journal of Clinical and Diagnostic Research, 7, 2173-2177. https://doi.org/10.7860/JCDR/2013/6460.3462

[22] Kumari, P., Rani, P. and Lakshmi, P. (2018) Evaluation of Microbiological Profile and Antibiogram of Aerobic Bacteria Isolated from Pus Samples. Journal of Medical and Allied Sciences, 8, 26-35. https://doi.org/10.5455/jmas.284747

[23] Shittu, A., Kolawole, D. and Oyedepo, E. (2010) A Study of Wound Infections in 
Two Health Institutions in Ile-Ife, Nigeria. African Journal of Biomedical Research, 5, 97-102. https://doi.org/10.4314/ajbr.v5i3.53994

[24] Dryden, M.S. (2009) Skin and Soft Tissue Infection: Microbiology and Epidemiology. International Journal of Antimicrobial Agents, 34, S2-S7. https://doi.org/10.1016/S0924-8579(09)70541-2

[25] Rijal, B.P., Satyal, D. and Parajuli, N.P. (2017) High Burden of Antimicrobial Resistance among Bacteria Causing Pyogenic Wound Infections at a Tertiary Care Hospital in Kathmandu, Nepal. Journal of Pathogens, 2017, Article ID: 9458218. https://doi.org/10.1155/2017/9458218

[26] Nirmala, S. and Sengodan, R. (2017) Aerobic Bacterial Isolates and their Antibiotic Susceptibility Pattern from Pus Samples in a Tertiary Care Government Hospital in Tamilnadu, India. International Journal of Current Microbiology and Applied Sciences, 6, 423-442. https://doi.org/10.20546/ijcmas.2017.606.050

[27] Mahdiyoun, S.M., Kazemian, H., Ahanjan, M., Houri, H. and Goudarzi, M. (2016) Frequency of Aminoglycoside-Resistance Genes in Methicillin-Resistant Staphylococcus aureus (MRSA) Isolates from Hospitalized Patients. Jundishapur Journal of Microbiology, 9, e35052. https://doi.org/10.5812/jim.35052 